\title{
Morphology and Growth Patterns of Developing Thalamocortical Axons
}

\author{
Irini Skaliora, Richard Adams, and Colin Blakemore \\ University Laboratory of Physiology, University of Oxford, Oxford OX1 3PT, United Kingdom
}

It is increasingly evident that the actions of guidance factors depend critically on the cellular and molecular context in which they operate. For this reason we examined the growth cone morphology and behavior of thalamic fibers in the relatively natural environment of a slice preparation containing the entire pathway from thalamus to cortex. Axons were labeled with Dil crystals and imaged with a laser-scanning confocal microscope for up to $8 \mathrm{hr}$. Their behavior was analyzed in terms of morphology, extension rates, shape of trajectory, frequency of branching, and percentage of time spent in advance, pause, and retraction. Thalamic fibers had distinct and stereotyped growth patterns that related closely to their position; within the striatum growth cones were small and elongated, rarely extending filopodia or side branches. Axons grew quickly, in straight trajecto- ries, with minimal pauses or retractions. When they reached the ventral intermediate zone, axons slowed down, often coming to a complete stop for up to several hours, and their growth cones became larger and more complex. During pauses there were continuous extensions and retractions of filopodia and/or side branches. When advance resumed, it was often to a different direction. These results demonstrate consistent regional variations in growth patterns that identify an unexpected decision region for thalamic axons. They provide the basis for examining the roles of guidance cues in an accessible yet intact preparation of the thalamocortical pathway and allow for an evaluation of previously suggested pathfinding mechanisms.

Key words: growth cones; development; axon guidance; timelapse confocal imaging; pathfinding; in vitro; thalamocortical
One of the most critical steps in the development of the CNS is the formation of the precise and stereotyped axon pathways that connect different structures to their targets. Despite the plethora of studies on axon guidance, the mechanisms that axons use to navigate through complex cellular environments such as the thalamocortical pathway remain elusive. Tracing studies in fixed brains have revealed the time course and morphological characteristics of axonal development and target invasion (Crandall and Caviness, 1984; Catalano et al., 1991, 1996; Ghosh and Shatz, 1992b; Agmon et al., 1993, 1995; Kageyama and Robertson, 1993; Miller et al., 1993; Schlaggar and O'Leary, 1994; Métin and Godement, 1996; Molnár et al., 1998), whereas in vitro experiments have indicated (1) the influence of target-derived factors on axon outgrowth (Yamamoto et al., 1989, 1992, 1997; Molnár and Blakemore, 1991, 1999; Bolz et al., 1992; Emerling and Lander, 1994; Hubener et al., 1995; Tuttle et al., 1995; Métin and Godement, 1996) and (2) the effects of specific guidance molecules on axons from cortical explants (Métin et al., 1997; Richards et al., 1997; Bagnard et al., 1998; Polleux et al., 1998). Although such studies of the thalamocortical pathway have revealed valuable information, they have always examined axons outside their natural environment. However, it is increasingly evident that guidance factors act in combination with other molecules and that their specific role depends on the spatiotemporal context in which they operate (Colamarino and Tessier-Lavigne, 1995; Stoeckli

\footnotetext{
Received Nov. 23, 1999; revised Feb. 4, 2000; accepted Feb. 10, 2000.

This study was supported by the Medical Research Council and the Oxford McDonnell-Pew Centre for Cognitive Neuroscience. I.S. held a European Union Research Training Grant. We thank Dr. Leo Chalupa for his commenting on an early draft of this manuscript.

Correspondence should be addressed to Dr. Irini Skaliora, University Laboratory of Physiology, University of Oxford, Parks Road, Oxford OX1 3PT, UK. E-mail: irini.skaliora@physiol.ox.ac.uk.

Copyright (C) 2000 Society for Neuroscience $\quad 0270-6474 / 00 / 203650-13 \$ 15.00 / 0$
}

and Landmesser, 1995; Püschel et al., 1996; Tuttle and O'Leary, 1998; Winberg et al., 1998; Hornberger et al., 1999; Isbister et al., 1999; Rose and Chiba, 1999).

There is considerable evidence that growth cone morphology, especially when examined together with the accompanying behavior, reflects the nature of the immediate local environment. For instance, growth cones tend to become larger and more complex when confronted with divergent pathways, the so-called decision regions of navigation, as opposed to nondecision regions, where growth cones are slender and streamlined (Raper et al., 1983; Tosney and Landmesser, 1985; Caudy and Bentley, 1986a; Bovolenta and Mason, 1987; Holt, 1989; Godement and Mason, 1993; Halloran and Kalil, 1994). Additionally, alterations in growth cone morphology have been correlated with interactions with cellular landmarks, often leading to modifications in trajectory (Caudy and Bentley, 1986b; Bovolenta and Dodd, 1990; O'Connor et al., 1990). Hence, by directly examining the dynamic morphology and growth patterns of thalamic growth cones, we can gain critical insight into the pathfinding mechanisms used by these axons.

Here we have investigated, for the first time, thalamic fibers in their intact cellular and biochemical environment, in a slice preparation that includes the ventrolateral thalamus and somatosensory cortex (Bernardo et al., 1986; Agmon and Connors, 1991). The changes in morphology and behavior of thalamic growth cones, as they advance through distinct cellular milieus, have provided clues to the mechanisms used by these axons to navigate toward their targets.

\section{MATERIALS AND METHODS}

Animals. Rat embryos of known gestational ages [embryonic day (E)15.5-E18] were obtained from an in-house breeding colony. The day of vaginal plug detection was considered as E0.

Surgical procedures. Embryos were delivered by caesarean section from 
pregnant rats deeply anesthetized with an intraperitoneal injection of Nembutal $(100 \mathrm{mg} / \mathrm{kg}$ ). The brains were dissected in cold saline (HBSS, Sigma, St. Louis, MO) supplemented with extra glucose (to a final concentration of $6.0 \mathrm{gm} / \mathrm{l}$ ) and embedded in $3 \%$ low melting agarose. Whole forebrain slices, including the ventrolateral thalamic nucleus and somatosensory cortex, were obtained by using a procedure modified from the literature (Bernardo et al., 1986; Agmon and Connors, 1991). Brains were embedded and placed with the ventral face down; a vertical cut through the tissue was made at a $35-45^{\circ}$ angle to the midline (depending on the age of the animal) through the most anterior part of the brain. The tissue rostral to the cut was discarded, and the remaining tissue was glued on to the vibratome stage. Slices were cut at a thickness of $400 \mu \mathrm{m}$ and left to equilibrate at room temperature for 30-60 min. We examined the slices under transillumination and selected those with clearly visible fiber bundles traversing the striatum, running between the ventrolateral thalamus and the lateral part of the putative somatosensory cortex. Then these slices were transferred to poly-L-lysine-coated Petri-Permount dishes containing F12-DMEM medium (Sigma), supplemented with N2 (1 ml/100 ml, Life Technologies, Gaithersburg, MD), glucose (6 gm/l), L-glutamine $(1.25 \mathrm{ml} / 100 \mathrm{ml})$, and antibiotics (penicillin-streptomycin, 1 $\mathrm{ml} / 100 \mathrm{ml}$; Sigma). Five to eight such preparations from different embryos of the same litter were made for each experiment and kept in a 5\% $\mathrm{CO}_{2}$ humidified incubator at $37^{\circ} \mathrm{C}$. In all experiments $3 \%$ calf serum was added to the medium in one-half of the dishes. No differences in axon outgrowth were found between the two conditions, and the data are pooled.

DiI labeling. Thalamic axons and their growth cones were labeled by the insertion of minute crystals of the carbocyanine dye DiI $\left(1,1^{\prime}\right.$ dioctadecyl-3,3,3,3'-tetramethylindocarbocyanine perchlorate; Molecular Probes, Eugene, OR) into the thalamus with a tungsten needle under a dissecting microscope. In such diagonally cut slices, with visible fiber bundles traversing through the striatum, the part of the thalamus present in the slice consists of the ventrolateral thalamic nucleus (Bernardo et al., 1986; Agmon and Connors, 1991). The slices were returned to the incubator and left overnight to allow for dye transport. With this method we were able to obtain small numbers of labeled thalamic axons in each slice (1-20), which were clearly identifiable and could be traced for long distances back toward the thalamus.

Time-lapse imaging of thalamic axons. Examination of the fluorescently labeled axons was performed with a confocal microscope to obtain clear optical sections within the relatively thick specimen. Most experiments were done on a Leica Fluovert confocal microscope (Nussloch, Germany), except one experiment that was done on a Bio-Rad confocal microscope (Richmond, CA). The dishes were scanned quickly under low power to identify slices that contained well labeled thalamic fibers and an uninterrupted pathway. After a preparation was selected, the dish was sealed and placed on the heated stage of the microscope maintained at $35^{\circ} \mathrm{C}$ with a thermostatically controlled heater. The medium was changed every 5-8 hr. At the end of the imaging session the slices were fixed in a $4 \%$ paraformaldehyde solution for $24-48 \mathrm{hr}$ for subsequent verification of the location of the imaged fibers.

We focused our analysis of thalamic axons on two regions of the thalamocortical pathway (see Fig. 1). The first is the part of the primordial internal capsule (IC) within the developing corpus striatum (ganglionic eminence); the second is the ventral intermediate zone (VIZ), at the border between the basal and dorsal telencephalon. Individual fibers and growth cones were observed with water immersion objectives [Leitz $25 \times$, PL Fluotar, numerical aperture (NA) $0.75 ; 50 \times$ NA 1.0 ] for up to $9 \mathrm{hr}$. Single frames or stacks of images at different depths were obtained at given time intervals ranging from 1 to $10 \mathrm{~min}$. In the first case the pinhole was open to maximize the thickness of the optical section and minimize the required laser intensity. Several frames (usually four) were averaged. The data points on the graphs (see Figs. 2-4, 6-8) represent the axon length at the times the images (either single frames or stacks) were collected. Although images were collected at regular intervals, in cases in which the axon length did not change between one frame and the next, data points sometimes were omitted from the final graph for reasons of clarity. Every effort was made to maximize the stability of the preparation and to maintain a constant focal plane during the experiment. However, it still proved necessary to adjust the focus periodically, because axons inevitably moved at variable angles to the plane of the slice. Frames in which the growth cones had moved out of focus during a particular sequence were excluded from calculations of growth rates. Confocal images were transferred to a Macintosh computer and analyzed further with the National Institutes of Health IMAGE software (Bethesda, MD).

Technical considerations. One of our concerns was to ensure that the analyzed axons and growth cones were healthy and representative of fibers growing in the intact brain. For these reasons axons were excluded from the study if any of the following applied: (1) beaded appearance, which might indicate photo damage induced by exposure to the fluorescent light; (2) growth cone escaping to the surface of the slice-to avoid artifacts induced by the cutting procedure, all imaged growth cones included in the analysis were located at least $30 \mu \mathrm{m}$ deep into the slice; (3) steady and gradual changes in rates of growth, because this could indicate a gradual deterioration of the axon attributable to either the culture conditions or damage induced by the laser. Furthermore, all imaging sessions began at least $12 \mathrm{hr}$ after preparation and labeling of the slices to avoid monitoring growth cones severed from the parent cell body (Harris et al., 1987).

Analysis. The behavior of axons was analyzed in terms of growth cone morphology, rates of growth, and percentage of time spent in extension, pause, and retraction. The length of the distal segment of the axon was measured from a distinctive point along the axon, such as a branch point or distinct inflection (but not a varicosity as these often were seen to move within the axon shaft), to the distal tip of the growth cone. For these measurements the outline of the axon was followed with the mouse cursor on the screen to obtain the real length of the axon, beyond the reference point. We chose this procedure, instead of marking only the final position of the growth cone, to avoid errors attributable to movements of the entire slice in the dish. These length values were divided by the total observation time to give a value for the net overall rate of advance. As an independent measurement the rates of growth were also calculated separately for shorter, defined periods for comparison between different growth patterns. These "instantaneous" rates were determined over periods of at least $10 \mathrm{~min}$ to avoid miscalculations attributable to "imaging noise" (i.e., the tip of the growth cone moving in and out of the focal plane). To determine growth cone activity (even if not accompanied by forward extension), we measured the total length of all visible side branches and filopodia. Finally, to assess the percentage of time spent in advance, pause, or retraction, we plotted the normalized axon length from each frame as a function of time; the duration of time spent in each mode was expressed as a function of the total time of observation.

\section{RESULTS}

Whole forebrain slices obtained from embryonic rats between E15.5 and E18 were labeled with DiI crystals placed in the thalamus, cultured overnight, and monitored with time-lapse confocal microscopy over the next 2-30 hr. In each slice a small number of fibers were labeled, and their growth cones were located at various positions along the thalamocortical pathway. All thalamic axons studied here $(n=25)$ followed a trajectory similar to that taken in vivo, initially extending anterolaterally out of the diencephalon and then turning dorsally through the developing striatum, within the primordial internal capsule. Axons that "escaped" to the surface of the slice often grew in aberrant directions and were excluded from the study. We concentrated our observations in two areas: (1) the segment of the internal capsule (IC) within the developing corpus striatum and (2) the adjacent ventral intermediate zone (VIZ) forming the transition region between the basal telencephalon and the cerebral wall (Fig. 1).

Most of the sequences that we studied were restricted to one locale, but occasionally we were able to follow growth cones over two consecutive locales, either as they moved from the IC into the VIZ or as they moved on from the latter to make their way toward the overlying cortex. The behavior of the axons in these two regions was analyzed in terms of growth cone morphology, shape of trajectory, rates of growth, and percentage of time spent in extension, pause, and retraction, measured over consecutive 5 min periods. Growth cone "activity" refers to dynamic morpho- 


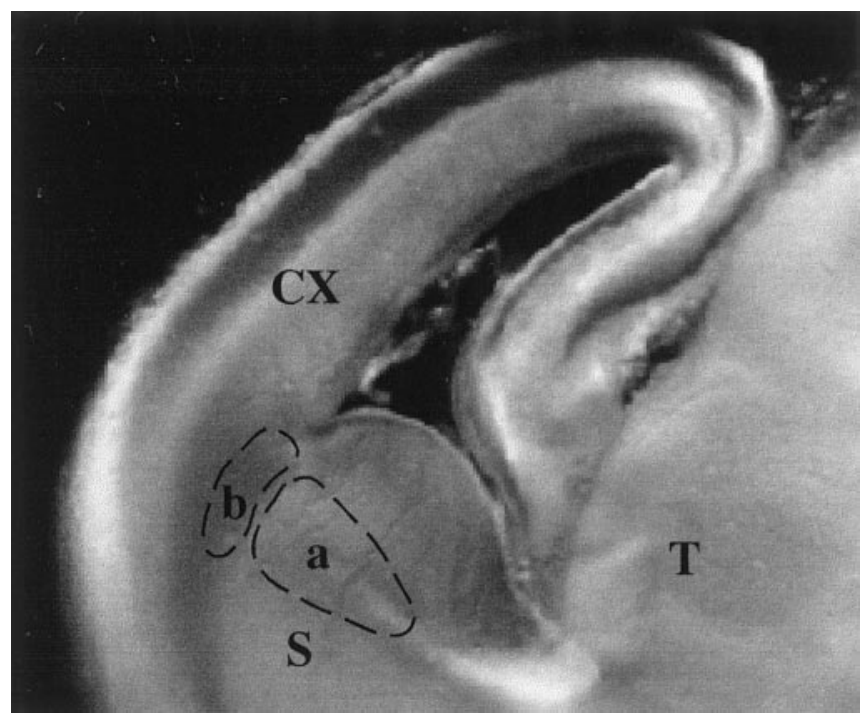

Figure 1. Photomicrograph, taken under transillumination, of a $400 \mu \mathrm{m}$ whole forebrain slice from the left hemisphere of an E17 rat brain cut at $45^{\circ}$ to the coronal and sagittal planes. Broken lines enclose the two locations in which growing axons were monitored: $a$, the region of the internal capsule; $b$, the ventral intermediate zone at the border between dorsal and ventral telencephalon. $C X$, Cortex; $T$, thalamus, $S$, corpus striatum.

logical changes of the growth cone, including extensions of filopodia and side branches in the most distal portion of the axon.

\section{Growth patterns along the thalamocortical path}

Thalamic fibers principally manifested three quite distinct types of behavior, which we call "tracking," "elongation," and "exploration." To be classified in one of these categories, an axon had to display a particular behavior (see criteria below) for a minimum of $30 \mathrm{~min}$ - and in all but one case they did so for a period of at least $1 \mathrm{hr}$. These growth patterns were highly stereotyped, and most axons (22 of 25) manifested only one type of behavior. The remaining three axons, all of which were studied for particularly long periods $(6-8 \mathrm{hr})$, showed evidence of transition between two behavioral patterns (see below). In these three cases the observation period was divided in two sequences, which were, for the purpose of classification, considered separately.

When classified as tracking ( $n=5$ sequences), axons advanced in straight trajectories, as if moving along preexisting "tracks." Their growth cones were small $(1-6 \mu \mathrm{m})$, sometimes not much wider than the diameter of the parent axon, and had simple morphology: spherical or elongated shape with no visible side branches or filopodia. They did not shift their direction, nor did they show signs of exploring the surrounding area but spent most of the time in forward extension, with few pauses and rare retractions (Fig. 2, side panels). Occasionally, a growth cone appeared to be growing in close association with another labeled axon that had already traversed the region. However, in such cases, wherever three-dimensional reconstruction was possible, the two neurites were found to be located in different focal planes, the illusion of an association between them being created by the similarity in the direction of their growth. Nevertheless, the possibility cannot be excluded that axons manifesting this behavior were fasciculating on other fibers that were not labeled. Examples of this tracking pattern are illustrated in Figure $2 A$, in which changes in normalized axon length are plotted as a function of time for two thalamic fibers from separate experiments.
The bottom graph describes the first hour of the imaging session for one of these axons on an expanded time scale to illustrate the momentary pauses or retractions, which would not be discernible with lower sampling frequencies (Fig. $2 B$ ).

Axons displaying elongation behavior $(n=11$ sequences) also advanced steadily, with only short pauses and minimal retractions, but along a meandering rather than a straight trajectory (Fig. $3 A, B)$. The growth cones, although still relatively small and lacking extensive lamellipodia or filopodial protrusions, were more elaborate and less uniform (Fig. 3, side panels), occasionally bifurcating transiently or emitting small side branches that were retracted rapidly.

In marked contrast to the growth patterns described so far was the exploration behavior ( $n=12$ sequences). Axons in this mode spent a much larger percentage of time pausing and/or retracting and, consequently, displayed considerably slower net advance. In addition, their growth cones were large (often up to $15 \mu \mathrm{m}$ in diameter) with a complex and irregular morphology, characterized by multiple filopodia and side branches extending in one or more directions (Fig. 4, top and bottom panels). The growth cone itself frequently bifurcated (Fig. 4, top middle panel) and occasionally even assumed a tripartite appearance (Fig. 4, top, second panel), although this was never seen to lead to bifurcation of the entire axon. Filopodia and lamellipodia were usually present at the growth cone, within $20 \mu \mathrm{m}$ of the most distal tip of the axon. Occasionally, similar spiky and veil-like protrusions emerged from more proximal locations along the axon shaft (Fig. 4, bottom, second, and third panels), sometimes as much as $60 \mu \mathrm{m}$ behind the growth cone. As can be seen in these examples, growth cone morphology was highly dynamic and continuously changing, but it very rarely assumed the simpler, elongated form observed in elongation behavior (but see below).

In the exploratory mode the growth cones seldom collapsed, even during long pauses, but remained highly motile. The graph in Figure 4 illustrates the growth pattern of an axon in the VIZ over a period of $8 \mathrm{hr}$. The symbols indicate the net distance covered by the axon in the duration of the experiment-obtained by measuring the length of the axon from a defined and stable point along the axon shaft to the most distal tip of the growth cone proper-as a function of time. Negative numbers indicate a retraction with respect to the state of the axon at the beginning of the recording session.

For the first $6 \mathrm{hr}$ the axon did not cover new ground and in fact had, during the first $2 \mathrm{hr}$, retracted from its initial position by $\sim 20$ $\mu \mathrm{m}$. At the end of this period of hesitation, during which the growth cone did not collapse but remained large, florid, and very motile, the axon resumed its forward advance at a different orientation (Fig. 4, last bottom panel). This change in behavior was accompanied by a change in morphology as the growth cone converted to the more streamlined form that characterized axons in the "elongation" mode. This observation is reminiscent of the recent finding that the morphology of retinal growth cones is related to their behavior (Mason and Wang, 1997). The behavior of this axon is shown on an expanded time scale in Figure 5 to illustrate graphically the contrast between the lack of forward advance of the axon and the active remodeling of the growth cone. The top graph plots the change in total side branch activity; the lengths of all (visible) side branches (examples of which are indicated by the arrows in Fig. 4) and filopodia were measured at regular intervals, added together, and normalized to the beginning of the sequence. Such measurements were certainly an underestimate of growth cone activity, since it is not possible to 

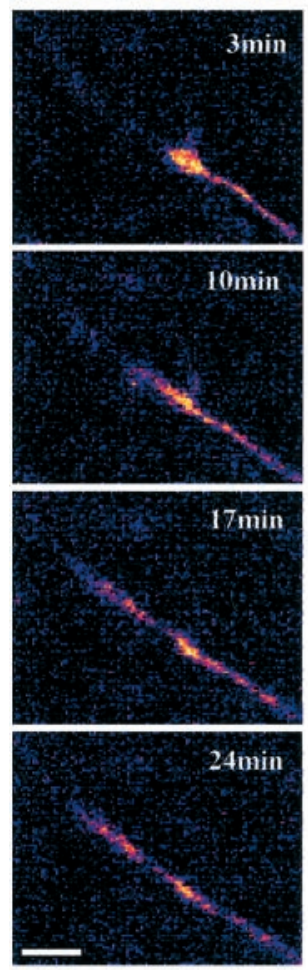

A

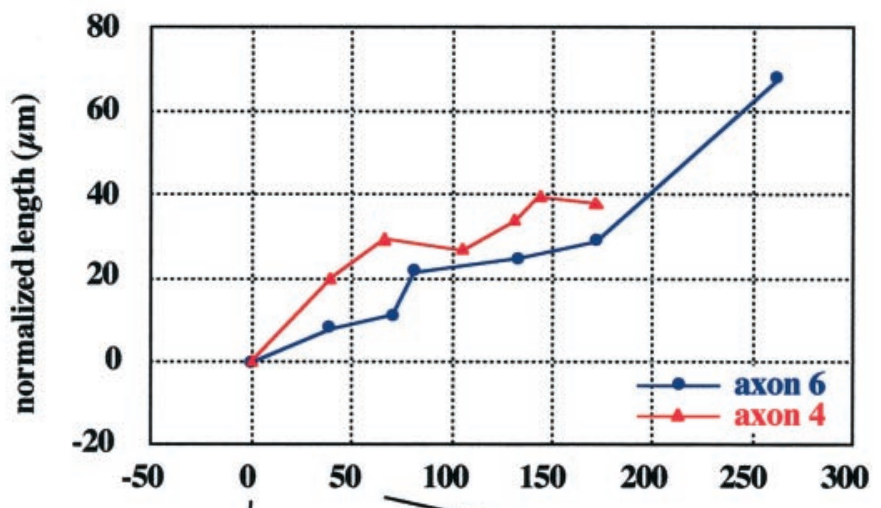

B

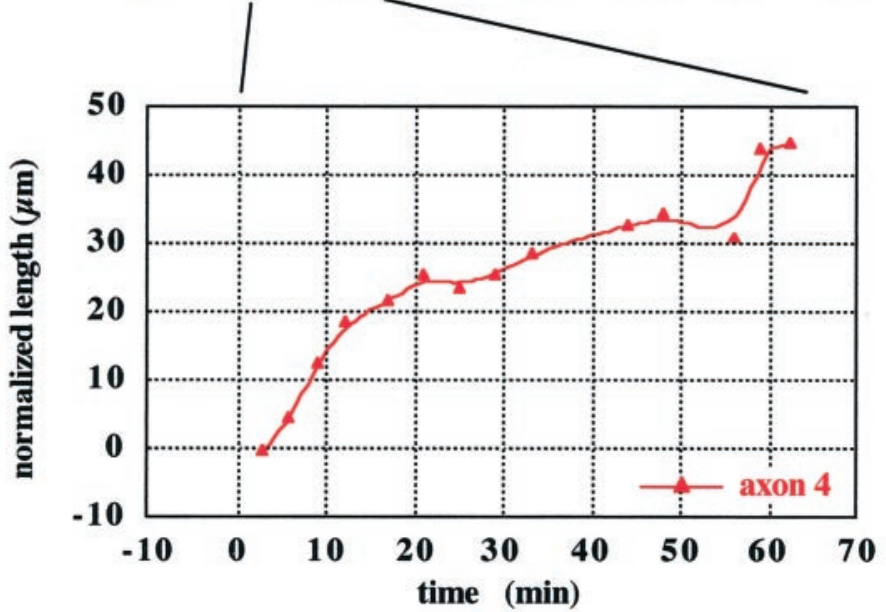

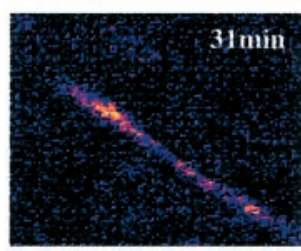
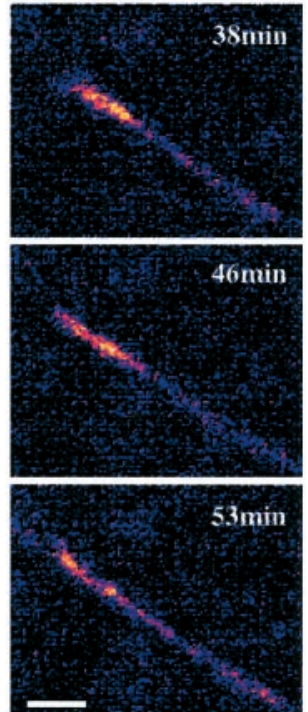

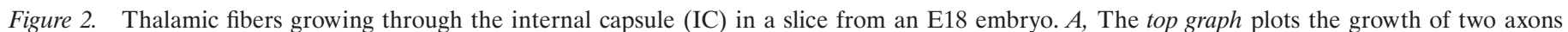

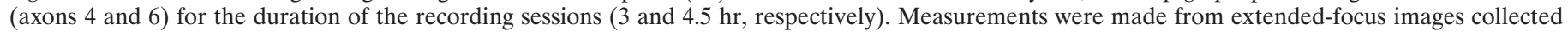

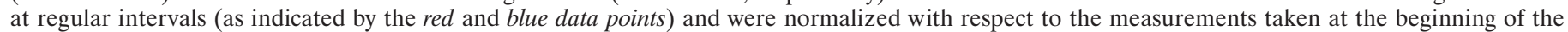

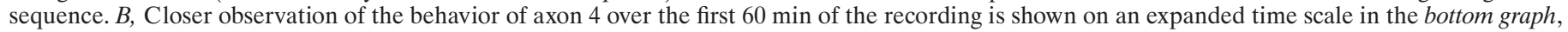

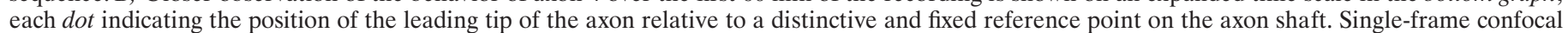

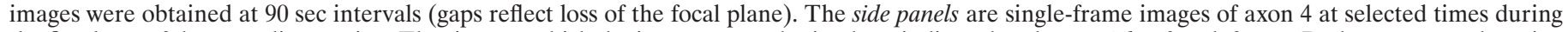

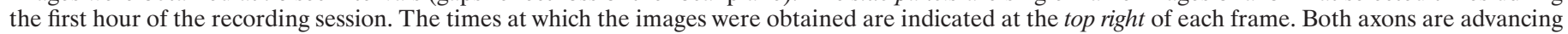

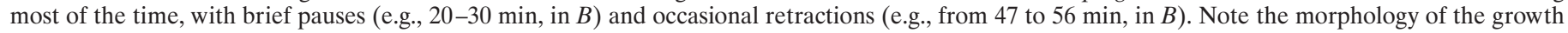
cone, which is small and streamlined with no side branches. Scale bar, $10 \mu \mathrm{m}$.

capture all three-dimensional changes in lamellar shape and extensions of transient protrusions in single confocal frames. For comparison, the bottom graph plots the change in length of the principal axon over the same time period.

Within the population of fibers in the exploring category was a subgroup of axons (3 of 12) with different morphology. The leading tip of these axons was often small and streamlined, and there were one or more side branches emerging from the distal 40-50 $\mu \mathrm{m}$ of the axon shaft. These branches often had small (occasionally barely detectable) growth cones of their own and were extending and retracting continually as if probing the surrounding area. These neurites were transitory, with a life span of 5-65 min.

Figure 6 shows an example of such an axon. At the beginning of the recording session this axon already had one side branch at $\sim 40 \mu \mathrm{m}$ behind the growth cone (Fig. 6, top left panel). During the observation period it had extended and retracted a further three side branches, while the principal axon as well as the original side branch (called the main side branch in Fig. 6) were pausing or retracting (Fig. 6, side panels). This behavior is illustrated in the graph, in which the normalized length of each of the branches is plotted separately as a function of time. Although they did not have growth cones as large and complex as those illustrated in the Figure 4, these axons were classified as being in exploratory mode on the basis of their growth pattern, which was characterized by prolonged pauses and retractions and slow overall rates of advance. As in this example, whenever we directly observed the emergence of a new branch $(n=5)$, this always occurred while the main axon was pausing. Likewise, the majority of cases in which side branches extended or retracted occurred during a pause in main axon growth (e.g., Figs. 4, 6, 7).

\section{Correlation between the behavior and location of growth cones}

We then examined whether the morphology and behavior of growth cones correlated with their location within the pathway from thalamus to cortex. Although there were overlapping characteristics and behavioral patterns, some conclusions were immediately obvious. Simply by playing back the animated sequences we could see that, within the IC, axons displayed either "tracking" or "elongation" but never "exploration" behavior. Growth cones in this region never had the highly complex morphology often encountered in the VIZ-even during the brief periods when the axons did pause (see below), growth cones remained simple and 

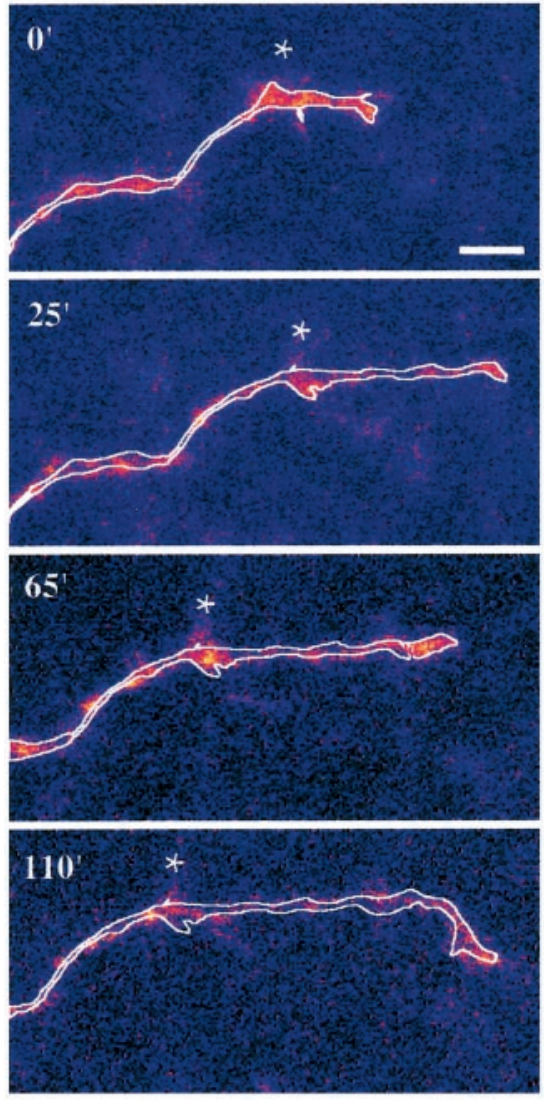

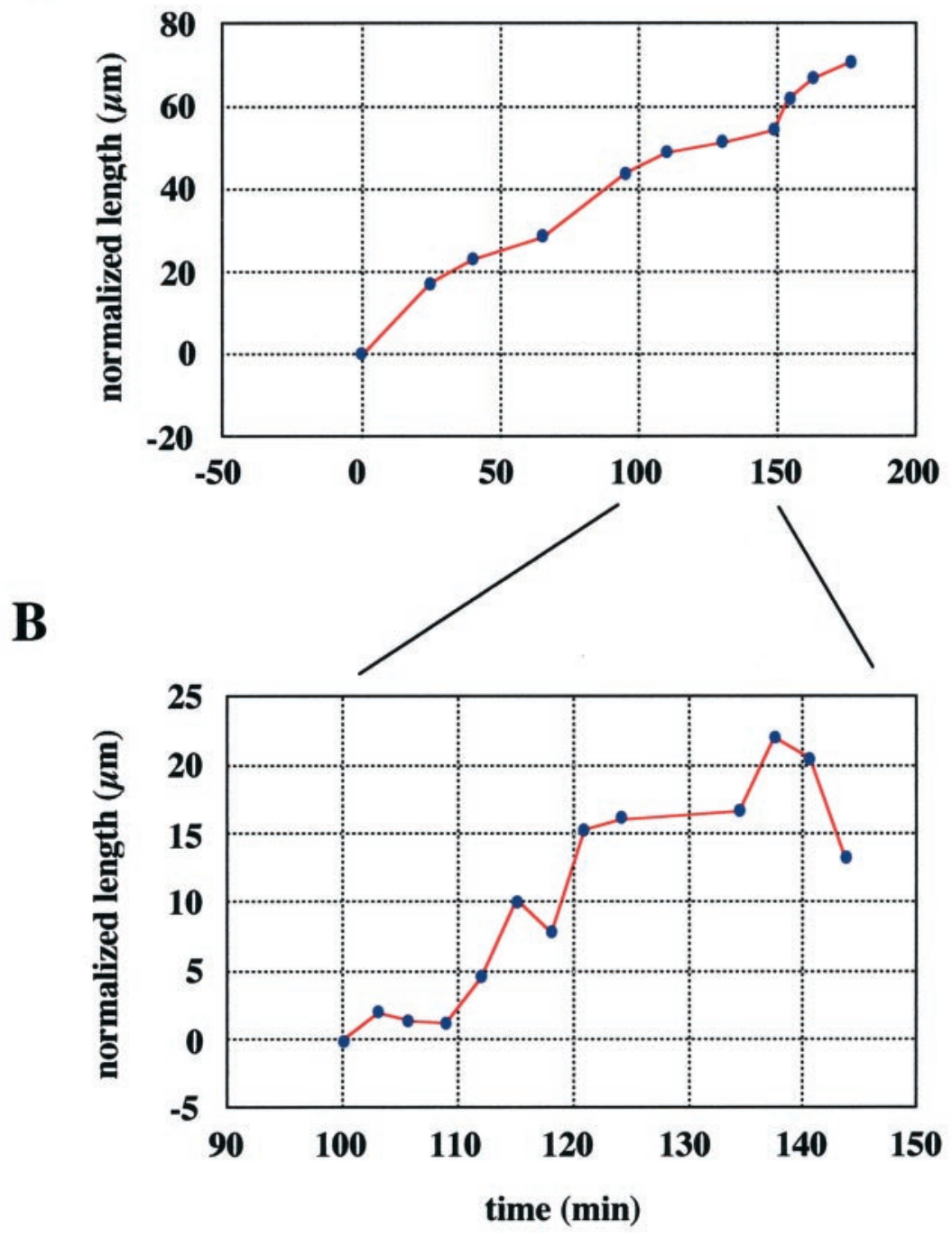

Figure 3. E16 thalamic fiber growing through the IC. Side panels are extended-focus images of the distal segment of the axon and its growth cone, collected at various times throughout a $3 \mathrm{hr}$ imaging session. The axon has been outlined for clarity. The times at which the stacks were collected are indicated at the top left of each image, and the star indicates a stable point along the axon for clearer illustration of axon extension. The top graph shows that it advanced at a relatively constant growth rate. The bottom graph, at an expanded time scale, provides a better view of the momentary pauses and retractions. Scale bar, $10 \mu \mathrm{m}$.

relatively small. Axons very rarely formed branches either adjacent to the growth cone or further back along the axon shaft. In addition, they very seldom shifted their trajectory and never retracted for $>10-15 \mu \mathrm{m}$. On the other hand, axons in the VIZ, even when advancing, never manifested the "growing-on-tracks" appearance. Their growth cones were always well defined and clearly distinguishable from the axon, and they did not advance in the absolutely straight trajectories encountered in axons of the tracking group. Most of them shifted directions at least once during the imaging session, and they routinely displayed extensive side branch activity, either from the growth cone itself (e.g., Fig. 7) or from the neurite shaft (e.g., Fig. 6) as they went through cycles of extension, pausing, and retraction. These qualitative differences (summarized in Table 1) were not related to the age of the animal from which the slices were prepared nor to the age of the slice once it had been removed from the animal.

To quantify further the extent to which particular behaviors were correlated with discrete locations in the path, we analyzed the shape of trajectory and the extension rates for each axon as well as the percentage of time they spent in advance, pause, and retraction. The net extension rate was calculated as the total distance covered by the leading tip of the axon divided by the total time of observation, over sequences of at least $30 \mathrm{~min}$. To determine the time spent in forward advance, pause, or retraction, we obtained the position of the distal tip of the growth cone proper from each frame and plotted it as a function of time. Then these values were used to calculate the fraction of all $5 \mathrm{~min}$ intervals in the sequence in which growth cones advanced, paused, or retracted.

Axons in the IC had relatively uniform extension rates ranging from 15 to $25 \mu \mathrm{m} / \mathrm{hr}$, with a mean of $17.3 \pm 4.4 \mu \mathrm{m} / \mathrm{hr}(n=11)$. In contrast, axons in the VIZ had more variable and significantly slower extension rates ranging from 2 to $16 \mu \mathrm{m} / \mathrm{hr}$, with a mean of $8.4 \pm 5.3 \mu \mathrm{m} / \mathrm{hr}(n=16)$. Interestingly, the "instantaneous" 

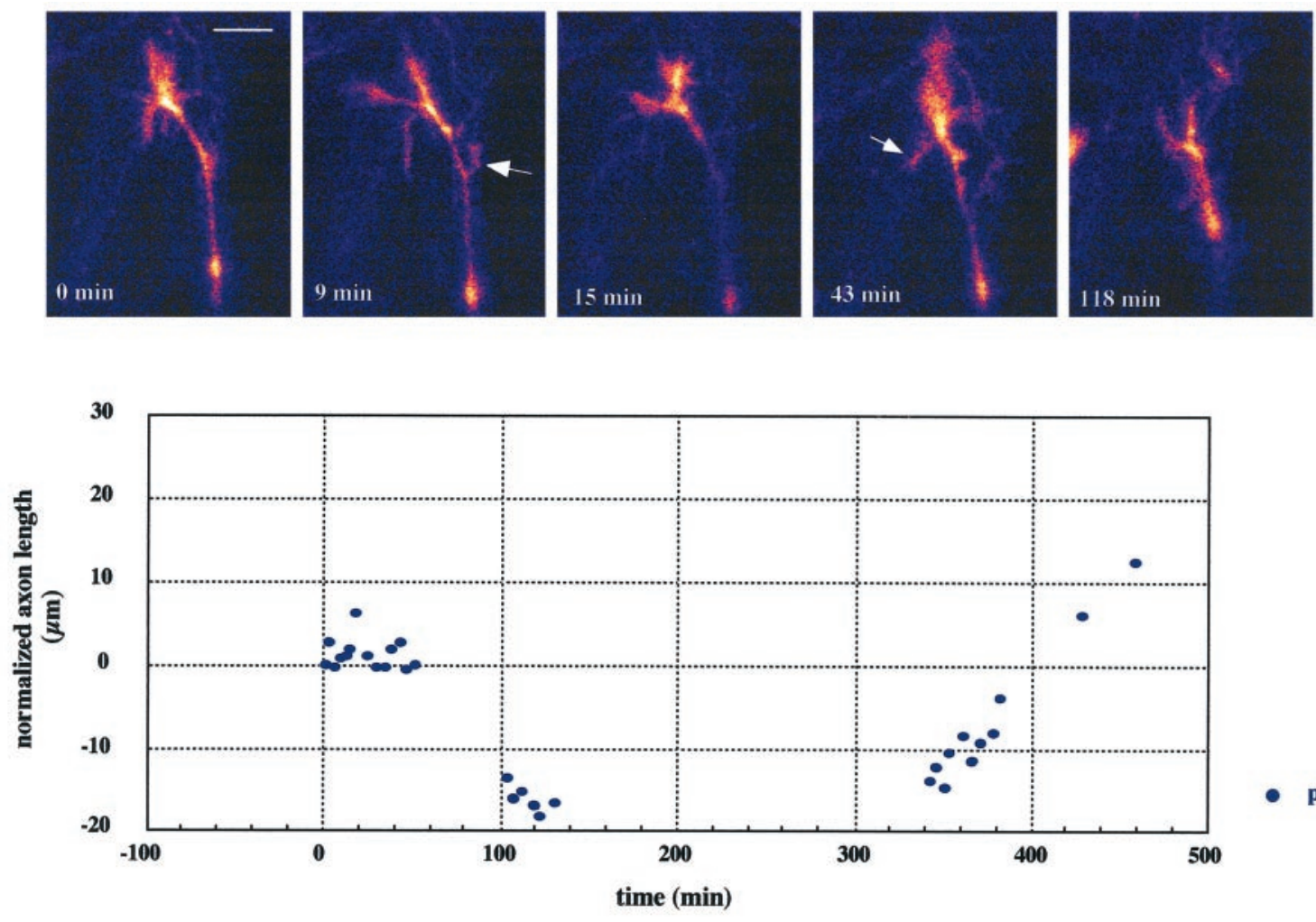

- principal axon length
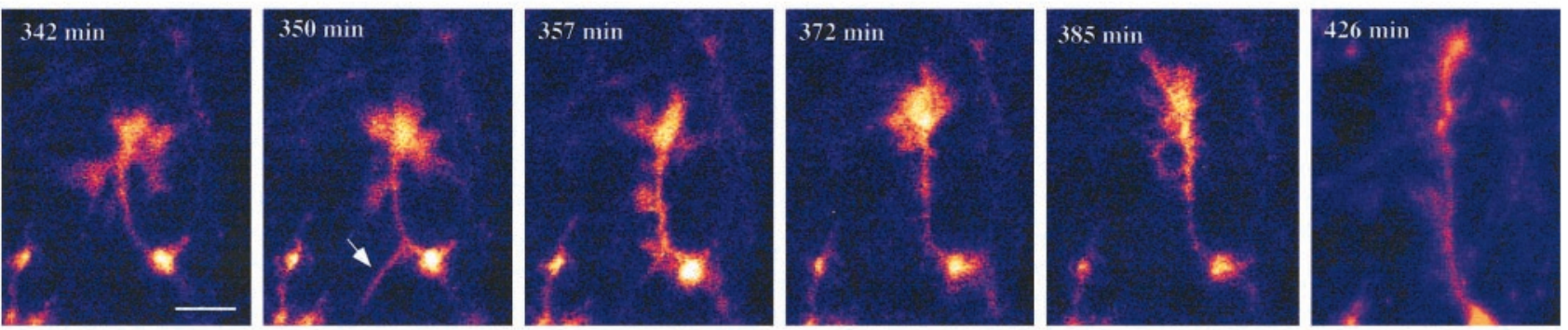

Figure 4. Thalamic axon with its growth cone located in the ventral intermediate zone (VIZ) of an E17 forebrain slice. Panels at the top and bottom are single confocal frames obtained at the times indicated. These images are framed to illustrate growth cone morphology and do not necessarily reflect the absolute position of the growth cone with respect to the slice. The graph illustrates the behavior of this axon for the 8 hr of the imaging session. Measurements were made from a stable inflection point further down along the axon shaft and were normalized to the beginning of the sequence. Dots indicate the principal axon length, i.e., the distance from the measuring point to the leading edge of the body of the growth cone (excluding filopodia and side branches, examples of which are indicated by the arrows of the leading segment of the axon). Periods lacking data points reflect either loss of the focal plane or deliberate changes in the area that was imaged. Although the out-of-focus images were not sharp enough to allow for accurate measurements, they confirmed that the growth cone was still in the field of view and had not manifested massive extensions or retractions. Note that the net forward growth rate is at its highest at the end of the $8 \mathrm{hr}$ imaging session, indicating the continuing good health of the slice. Scale bar, $10 \mu \mathrm{m}$.

speed of growth during short periods of advance (5-30 min) was similar between axons in the two locales (Table 2), in each case sometimes reaching up to $100 \mu \mathrm{m} / \mathrm{hr}$. Indeed, when the average speed of growth was calculated separately for periods of extension alone, the rates for axons in the IC, although somewhat faster, were not significantly different from those in the VIZ.

This would seem to indicate that the twofold difference in net extension rates between the two groups of axons may be explained by a difference in the fractions of time spent in advance versus pause and retraction. Indeed, the duration of individual pauses in the internal capsule was between 5 and $50 \mathrm{~min}$, whereas in the intermediate zone the pauses could last up to $6.5 \mathrm{hr}$. Furthermore, we found that axons in the VIZ spent approximately one-half as much time in extension and three times as much time in pausing and withdrawing as compared with axons in the IC (Table 2).

Finally, we analyzed shifts in trajectory, defined as changes in the direction of forward advance of at least $20^{\circ}$. Only 1 of 11 axons in the internal capsule made such a turn, whereas close to one-half of the fibers in the VIZ (7 of 16) made single or multiple turns of between 20 and $50^{\circ}$ (see Table 1). This was not a consequence of the duration of the imaging sessions, which was similar in the two groups (mean \pm SD of the duration of sequences in the IC and VIZ, $153 \pm 61$ and $171 \pm 99 \mathrm{~min}$, respectively).

Interestingly, in the cases in which we were able to observe turning behavior directly, the mechanistic aspects of it were different between the two groups. Axons in the internal capsule 


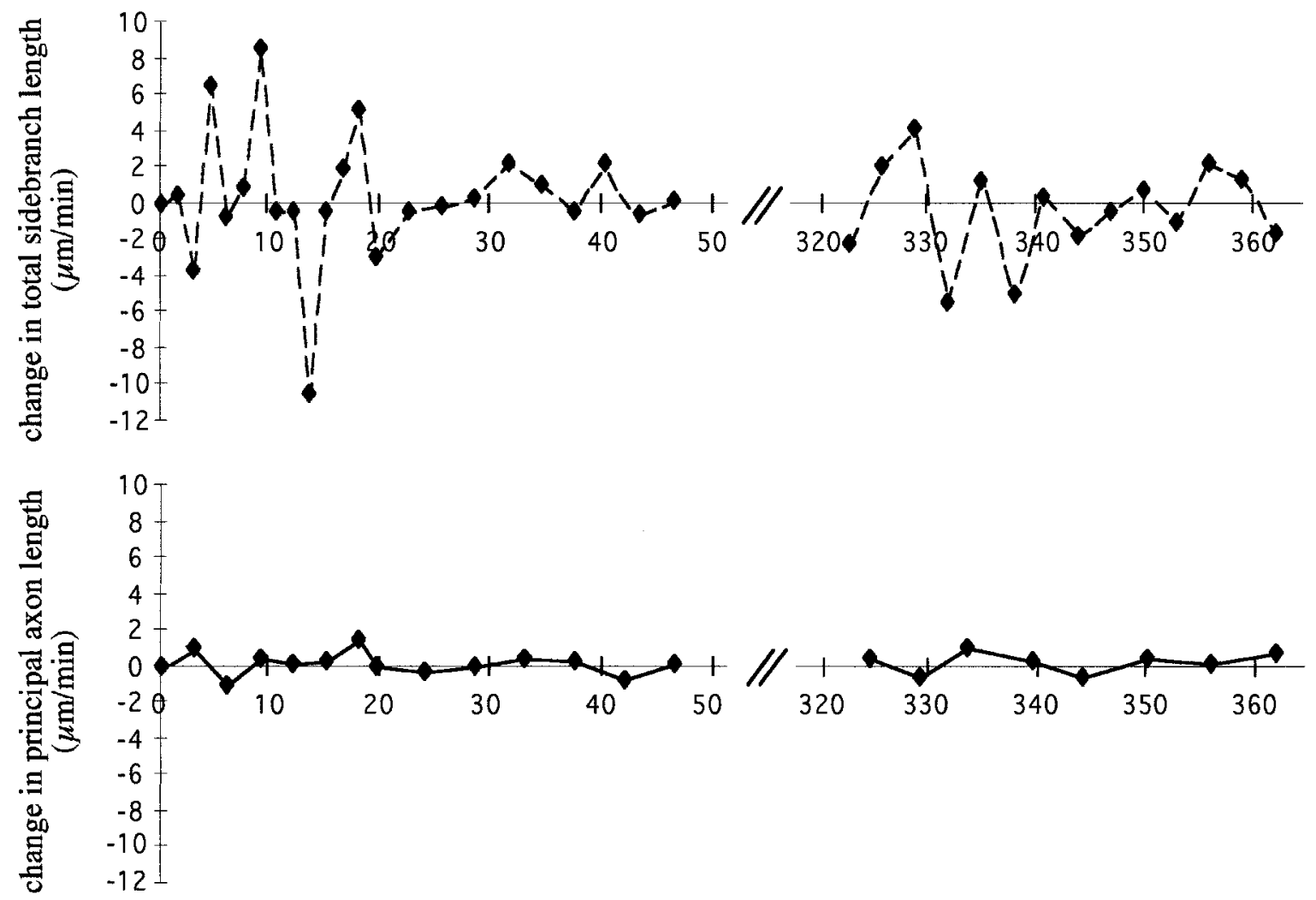

\section{time (min)}

Figure 5. "Exploratory" behavior. The graphs illustrate on expanded time scales the behavior of the axon shown in the previous figure. The red symbols and line indicate the changes in total side branch length-i.e., the summed length of all visible filopodia and side branches of the leading tip of the axon. The blue symbols and trace indicate the principal axon length, i.e., the distance from a stable measuring point to the most distal tip of the body of the growth cone. Both measurements are normalized to the respective measurements made at the beginning of the sequence. Note the lack of net advance (blue trace) and the considerable "stationary" movement (red trace). Negative numbers in either case indicate retractions with respect to the position at the onset of the observation period.

shifted direction by gradually curving while in full extension (see Fig. 2, side panels). In contrast, axons located in the intermediate zone always changed their trajectory immediately after a pause, either by following one branch of a bif urcating growth cone or by making a sharp turn toward the side from which they had just withdrawn a side branch. The latter behavior is shown in the example in Figure 7, in which the extensions of the main axon and of the side branch are plotted separately to contrast their behaviors. At the onset of the sequence the main neurite is inactive with its growth cone in a collapsed state (Fig. 7, left panel, open arrow), whereas the side branch is highly motile, having itself bifurcated and with a veil-like structure protruding from one segment (Fig. 7, left panel, filled arrow). As the side branch gradually retracts back into the axon shaft, the principal neurite is activated progressively (Fig. 7, second and third panels). After 45 min the side branch is barely visible whereas the main axon continues to extend forward, having shifted its course by $\sim 45^{\circ}$ toward the direction previously taken by the side branch (Fig. 7, right panel). Although we were not able to follow this sequence long enough to determine whether the shift in direction constituted a persistent change in trajectory, this is precisely the course this axon (which was located in the VIZ) would have had to take to enter the overlying cortex.

\section{Transitions of behavior}

Having documented the close correlation between growth cone location and behavior, we then examined more closely all individual sequences of growth cones located at the borders of the IC and VIZ to see whether it was possible to detect transitions in behavior. We found three such cases. One example has been illustrated already in Figure 4 in which the axon, after having spent $>6 \mathrm{hr}$ in pause/retraction, a behavior clearly classified as exploration on the basis of the outlined criteria, then began to move more purposefully forward and its growth cone assumed a simpler and more streamlined shape. Hence, on the basis of the same criteria, the sequence after $385 \mathrm{~min}$ in Figure 4 was classified as elongation (see Fig. 4, last panel).

The other two cases of transitions were of the opposite sign, in which axons with small and simple growth cones, advancing at a fairly steady rate were, in the latter part of the recording, found to spend more time pausing and retracting. Such an example is illustrated in Figure 8, in which the net advance (normalized length) of the axon was plotted as a function of time. During the first hour of the recording the axon was extending fairly steadily, had a relatively simple morphology (Fig. 8, first three panels), and therefore was classified as elongating. However, in the remaining $5 \mathrm{hr}$ of the observation time the axon slowed down, its growth 

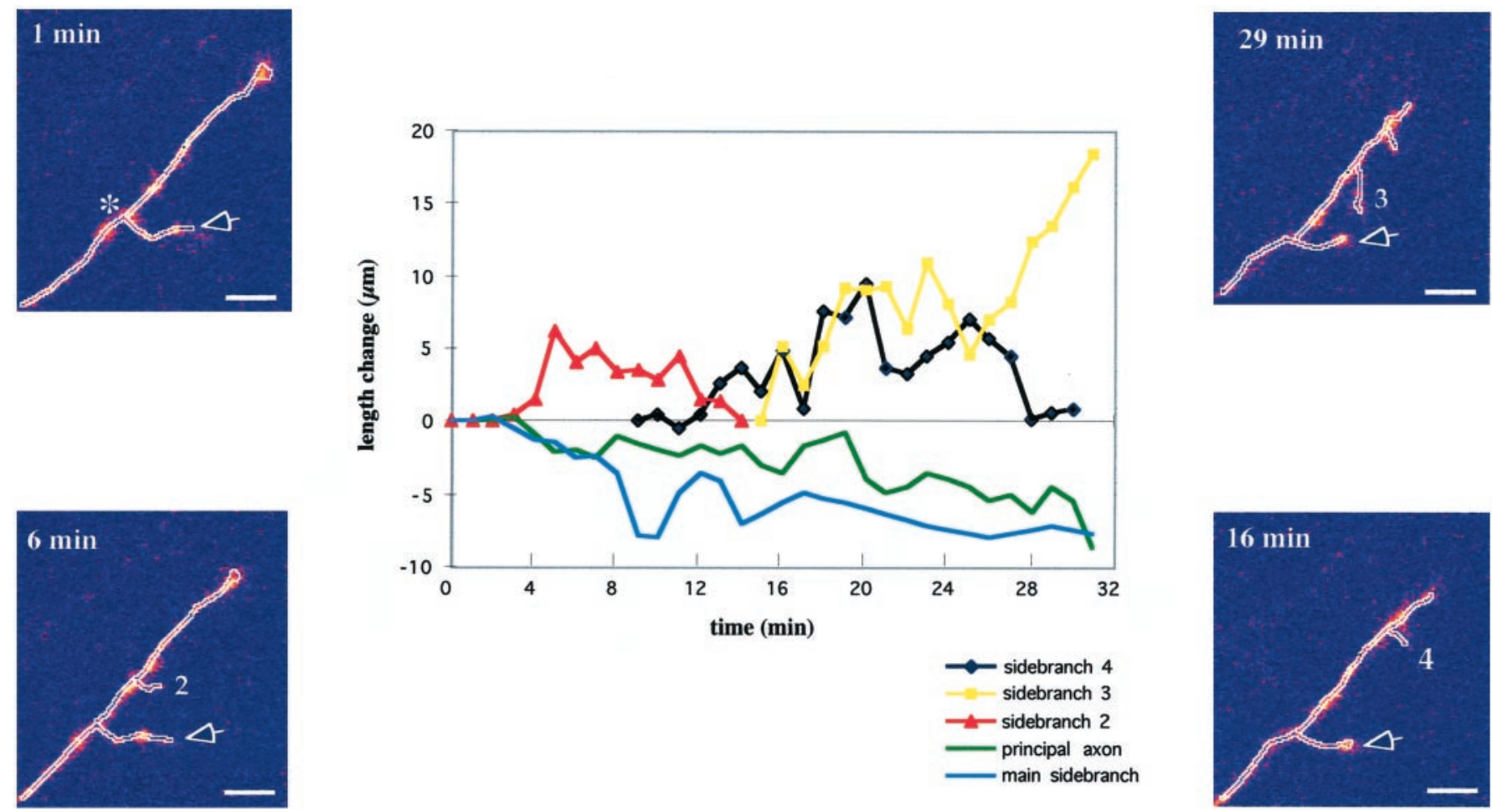

Figure 6. Side branch exploration of an axon for which the leading segment was in the VIZ, in a slice that was obtained from an E18 rat embryo. The four side panels are single-frame confocal images at selected times during a 30 min imaging session (times indicated at top left of each panel). The graph illustrates the behavior of each branch on this axon separately. Measurements for the principal axon and the main side branch were made from the point of bifurcation of the main side branch (star in top left panel) and normalized to the beginning of the recording session, The principal axon (green) as well as the main side branch (light blue) are primarily pausing, whereas side branches 2 (red), 3 (yellow), and 4 (black) along the axon shaft are being extended and retracted continually. The axon and branches in the four panels have been outlined for clarity. Scale bar, $10 \mu \mathrm{m}$.

cone became larger and more complex, and there were long pauses interrupted by momentary extensions and retractions, all distinguishing features of exploration behavior. In both examples of this type of transition the change in behavior was not attributable to a gradual deterioration of the slice because (1) the reduced extension rate was not accompanied by a collapsed growth cone; on the contrary, growth cones became enlarged and more elaborate, and (2) other axons in the same slice, imaged for comparable durations, did not show a similar reduction in growth rate.

Although rare, these transitional behaviors were particularly interesting because of the locations in which they were observed. The first example (transition from exploration to elongation) occurred at the lateral border of the intermediate zone as the growth cone was about to exit the VIZ and grow into the cerebral wall. The other two cases (transition from elongation to exploration) occurred at the border between the striatum and the cerebral wall as the growth cone was entering the VIZ. None of the remaining 22 sequences contained evidence of transitional behaviors.

\section{DISCUSSION}

This is the first report of the behavior of living thalamic axons as they grow toward their cortical targets in a slice preparation that contains the entire uninterrupted pathway between the thalamus and the cortex. We show that thalamic fibers follow the same trajectory as in vivo and exhibit distinct behaviors characteristic of the region through which they are growing. In the internal capsule they grow faster, in straight trajectories, with minimal pausing or exploring the surroundings. Growth cones are small and simple, rarely extending filopodia or side branches. When they reach the ventral intermediate zone, they slow down, and the growth cones become larger and considerably more complex. Axons may even come to a complete stop, pausing for up to several hours. During these pauses the growth cones are usually at their most eff usive, with continuous extensions and retractions of filopodia and lamellipodia. When net advance resumes, it is often in a different direction, appropriate to their final destination. These distinct behaviors can be interpreted in the context of multiple guidance cues and help in the evaluation of models of pathfinding, based on observations from fixed material and experiments in tissue culture.

\section{Axon guidance within the striatum}

What cues could account for the shapes and behaviors of growth cones that we observed in the IC? Both the compact growth cones and simple growth patterns along straight trajectories are suggestive of growth within fascicles of axons or radial glia (Lopresti et al., 1973; Tosney and Landmesser, 1985; Bovolenta and Mason, 1987; Kim et al., 1991; Williams et al., 1991; Halloran and Kalil, 1994; Brittis et al., 1995). Nevertheless, we did not directly observe labeled axons literally growing in contact with each other. There are at least two, nonexclusive reasons for this apparent discrepancy: (1) we deliberately labeled very few axons in each slice, so the probability of close neighbors being labeled was low; (2) our crystal placement was intended to label only thalamic axons. Therefore, the axons we studied may have been fasciculating with unlabeled fibers from other origins. Previous studies 


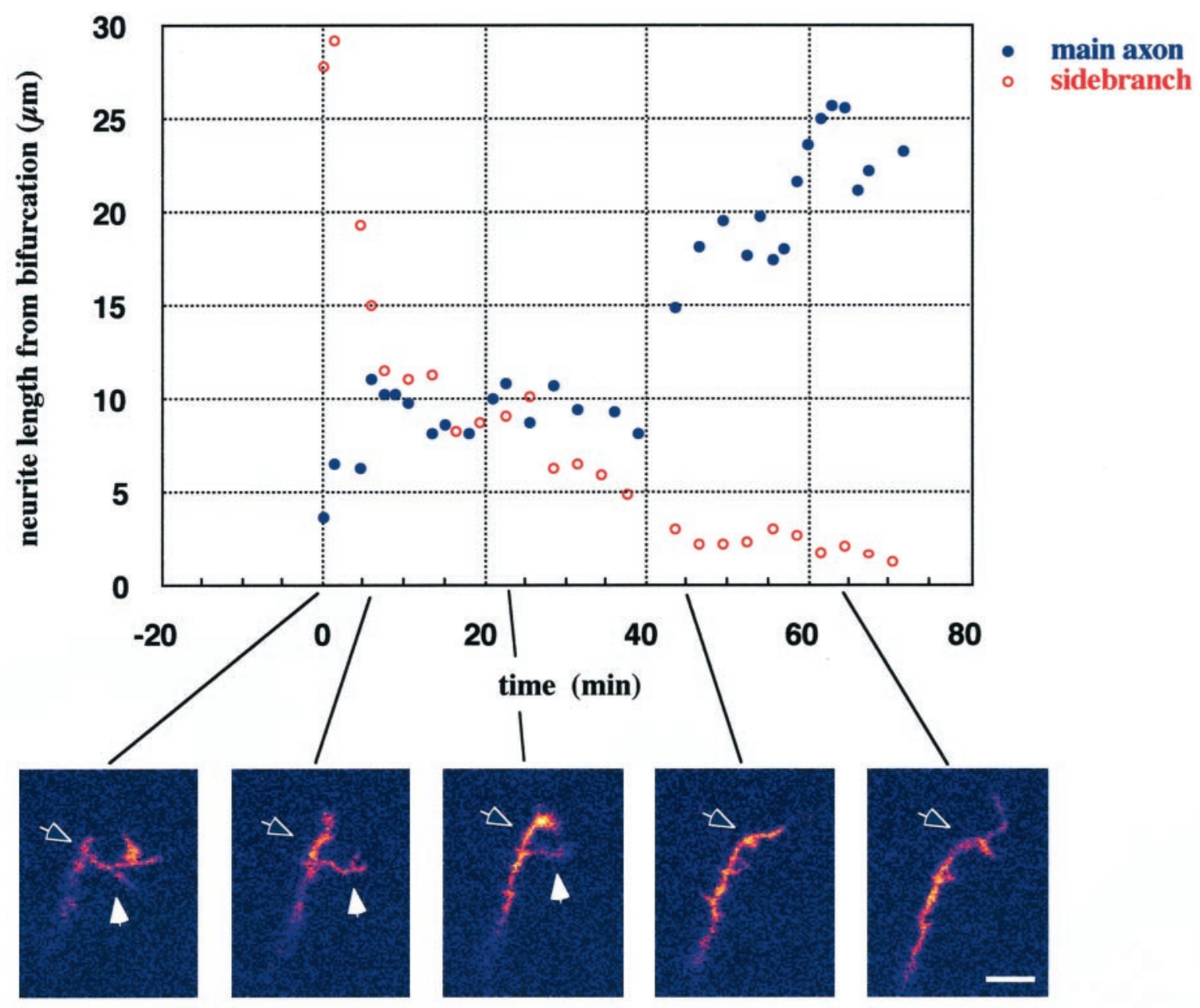

Figure 7. Growth dynamics. The graph illustrates the contrasting behaviors of the main branch (blue, filled circles) and the side branch (red, open circles) of a thalamic axon in the VIZ. The panels at the bottom are single-frame confocal images collected at the times indicated by the solid lines. The lengths of the main axon (open arrow) and of the side branch ( filled arrow) are measured from the stable bifurcation point at different times during a 70 min imaging session. Initially, most of the activity occurs in the side branch, which has branches of its own and appears to explore the surrounding territory. Gradually, the side branch becomes more quiescent and eventually retracts into the axon shaft; at the same time the main axon becomes "activated": its growth cone becomes enlarged and it seems to take over the exploration. Scale bar, $10 \mu \mathrm{m}$.

have suggested that thalamic fibers associate with several other axonal systems, which also could play a role in guiding them to their targets (McConnell et al., 1989; Ghosh et al., 1990; Ghosh and Shatz, 1992a; Mitrofanis and Baker, 1993; Mitrofanis and Guillery, 1993; Molnár and Blakemore, 1995; Métin and Godement, 1996; Molnár et al., 1998) (see also Bicknese et al., 1994; Miller et al., 1995). The fact that not all axons in the IC manifest the tracking pattern further indicates that growth cones retain the ability to respond individually to pathfinding signals.

Ultimately, the growth patterns we observed have to be explained in molecular terms. The signaling factors that might be guiding thalamic axons through the striatum are beginning to be identified. At least two secreted proteins, netrin-1 and semaphorin $\mathrm{E}$ (semE), that are expressed in the developing striatum (Serafini et al., 1996; I. Skaliora, W. Singer, H. Betz, and A. Püschel, unpublished results) were found to attract axons from cortical explants (Métin et al., 1997; Richards et al., 1997; Bagnard et al., 1998). These or other guidance cues could have similar effects on thalamic axons.

Nonetheless, although such signals are probably important for establishing the direction of growth, they cannot by themselves account for the axonal morphology and behavior that we observed. We can think of three possible ways to explain the small size, streamlined morphology, lack of branching, and signs of fasciculated growth. First, thalamic axons could be strongly attracted to other fibers that express growth-supporting molecules, such as the immunoglobulin/fibronectin type III adhesion molecules (Stoeckli and Landmesser, 1995). Second, growth cones could be responding to molecular components in the developing striatum that encourage them to adopt active elongation behavior and discourage them from branching (Llirbat and Godement, 1999). Third, these features could indicate the presence of inhibitory signals. The strongest candidate among the molecules already shown to be expressed in this region is semaphorin D (semD) (Giger et al., 1996; Skaliora et al., 1998), which has been shown to repel several types of axons (including thalamic) in culture (Luo et al., 1993; Messersmith et al., 1995; Püschel et al., 1995; Bagnard et al., 1996, 1998; Varela-Echavarria et al., 1997; Polleux et al., 1998). Although in vivo semD does not appear to set up an absolute barrier, because thalamic fibers still succeed in entering and crossing the striatum, it may be acting as a partial repellent, allowing growth but preventing branching or synapse 


\begin{tabular}{|c|c|c|c|c|c|c|c|}
\hline Axon & Sequence & Age & Growth pattern & Location & Duration & Sidebranch activity & Change in direction \\
\hline 1 & 1 & E18 & Tracking & IC & 175 & No & No \\
\hline 2 & 2 & E18 & Tracking & IC & 260 & No & No \\
\hline 3 & 3 & E17 & Tracking & IC & 105 & No & No \\
\hline 4 & 4 & E17 & Tracking & IC & 75 & No & No \\
\hline 5 & 5 & E16.5 & Tracking & IC & 180 & No & No \\
\hline 6 & 6 & E16 & Elongation & IC & 180 & No & $45^{\circ}$, single \\
\hline 7 & 7 & E15.5 & Elongation & IC & 130 & No & No \\
\hline 8 & 8 & E17 & Elongation & IC & 230 & Yes & No \\
\hline 9 & 9 & E18 & Elongation & IC & 65 & No & No \\
\hline 10 & 10 & E17 & Elongation & VIZ & 85 & Yes & No \\
\hline 11 & 11 & E17 & Elongation & VIZ & 340 & No & $50^{\circ}$, multiple \\
\hline 12 & 12 & E16 & Elongation & VIZ & 155 & & No \\
\hline 13 & 13 & E16.5 & Elongation & VIZ & 195 & Yes & No \\
\hline \multirow[t]{2}{*}{14} & 14 & E17 & Elongation & $\mathrm{IC} \rightarrow$ & 165 & No & No \\
\hline & 15 & E17 & Exploration & $\rightarrow \mathrm{VIZ}$ & 215 & Yes & No \\
\hline \multirow[t]{2}{*}{15} & 16 & E17.5 & Elongation & $\mathrm{IC} \rightarrow$ & 120 & No & No \\
\hline & 17 & E17.5 & Exploration & $\rightarrow \mathrm{VIZ}$ & 270 & Yes & No \\
\hline 16 & 18 & E17 & Exploration & VIZ & 95 & No & No \\
\hline 17 & 19 & E16.5 & Exploration & VIZ & 155 & No & $45^{\circ}$, single \\
\hline 18 & 20 & E17 & Exploration & VIZ & 240 & No & $30^{\circ}$, multiple \\
\hline 19 & 21 & E16 & Exploration & VIZ & 70 & Yes & No \\
\hline 20 & 22 & E17 & Exploration & VIZ & 140 & Yes & $30^{\circ}$, multiple \\
\hline 21 & 23 & E18 & Exploration & VIZ & 30 & Yes & No \\
\hline 22 & 24 & E18 & Exploration & VIZ & 70 & Yes & $45^{\circ}$, single \\
\hline 23 & 25 & E17 & Exploration & VIZ & 170 & No & $40^{\circ}$, single \\
\hline 24 & 26 & E16 & Exploration & VIZ & 220 & Yes & No \\
\hline \multirow[t]{2}{*}{25} & 27 & E17 & Exploration & VIZ & 385 & Yes & $35^{\circ}$, single \\
\hline & 28 & E17 & Elongation & $\mathrm{VIZ} \rightarrow$ & 75 & No & No \\
\hline
\end{tabular}

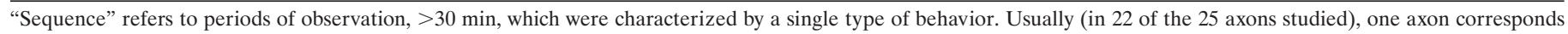

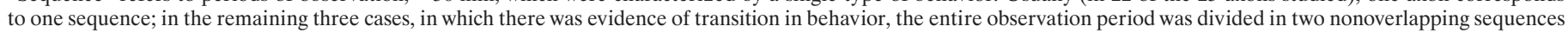

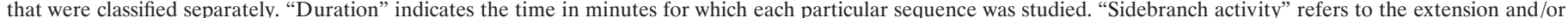

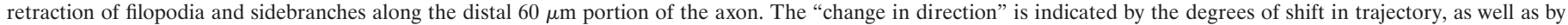

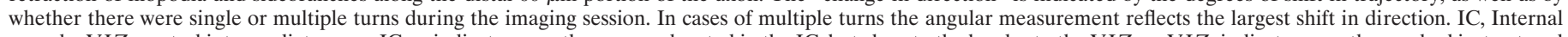

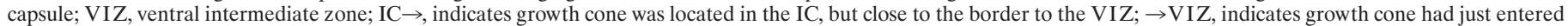
the VIZ; VIZ $\rightarrow$, indicates growth cone was located at the dorsolateral border of the VIZ, about to exit the region outlined in Fig. 1, toward the overlying cortex.

Table 2. Quantification of axonal behavior in the two locations

\begin{tabular}{lllllrr} 
& & $\begin{array}{l}\text { Net growth rate } \\
(\mu \mathrm{m} / \mathrm{hr})\end{array}$ & $\begin{array}{l}\text { Rate during advance } \\
(\mu \mathrm{m} / \mathrm{hr})\end{array}$ & \% Advance & \% Pause & \% Retraction \\
\hline IC & Mean & 17.26 & 55.01 & 79.40 & 12.86 & 7.73 \\
& SD & 4.44 & 29.67 & 10.54 & 5.25 & 7.37 \\
VIZ & Mean & 8.39 & 42.34 & 37.53 & 37.56 & 24.91 \\
& SD & 5.34 & 12.67 & 13.50 & 16.14 & 11.11
\end{tabular}

Net growth rate was calculated as the change in axon length over the total observation time, and rate during advance is the change in axon length during periods of advance only. The percentage of advance, pause, and retraction values indicates the percentage of consecutive $5 \mathrm{~min}$ intervals that the axons spent in advance, pause, and retraction, respectively (also see Materials and Methods). For the two axons that moved from the IC into the VIZ during the period of observation, these parameters were calculated separately for each location.

formation. Such functions have been demonstrated for semaphorins in different species (Matthes et al., 1995; Isbister et al., 1999) and are also reminiscent of retinal axons in culture that are inhibited from branching, but are not prevented from extending, on a substrate of caudal tectal membranes (Roskies and O'Leary, 1994). Interestingly, thalamic axons branch selectively within layer 4, the only cortical layer that does not express any of the semaphorin genes (Skaliora et al., 1998). Hence, semD could provide a surround repulsion that prevents branching and synapse formation in inappropriate regions. These three alternatives are not mutually exclusive, and they would all be consistent with our findings.

\section{Axon guidance in the ventral intermediate zone}

The characteristic changes in the morphology and behavior we observed in this area are all hallmarks of axons reaching transition points in their paths, such as decision regions or entry into targets. For instance, in the optic chiasm, one of the better studied and unambiguous decision areas, growth cones tend to be large and complex, as axons go through protracted pauses and have 

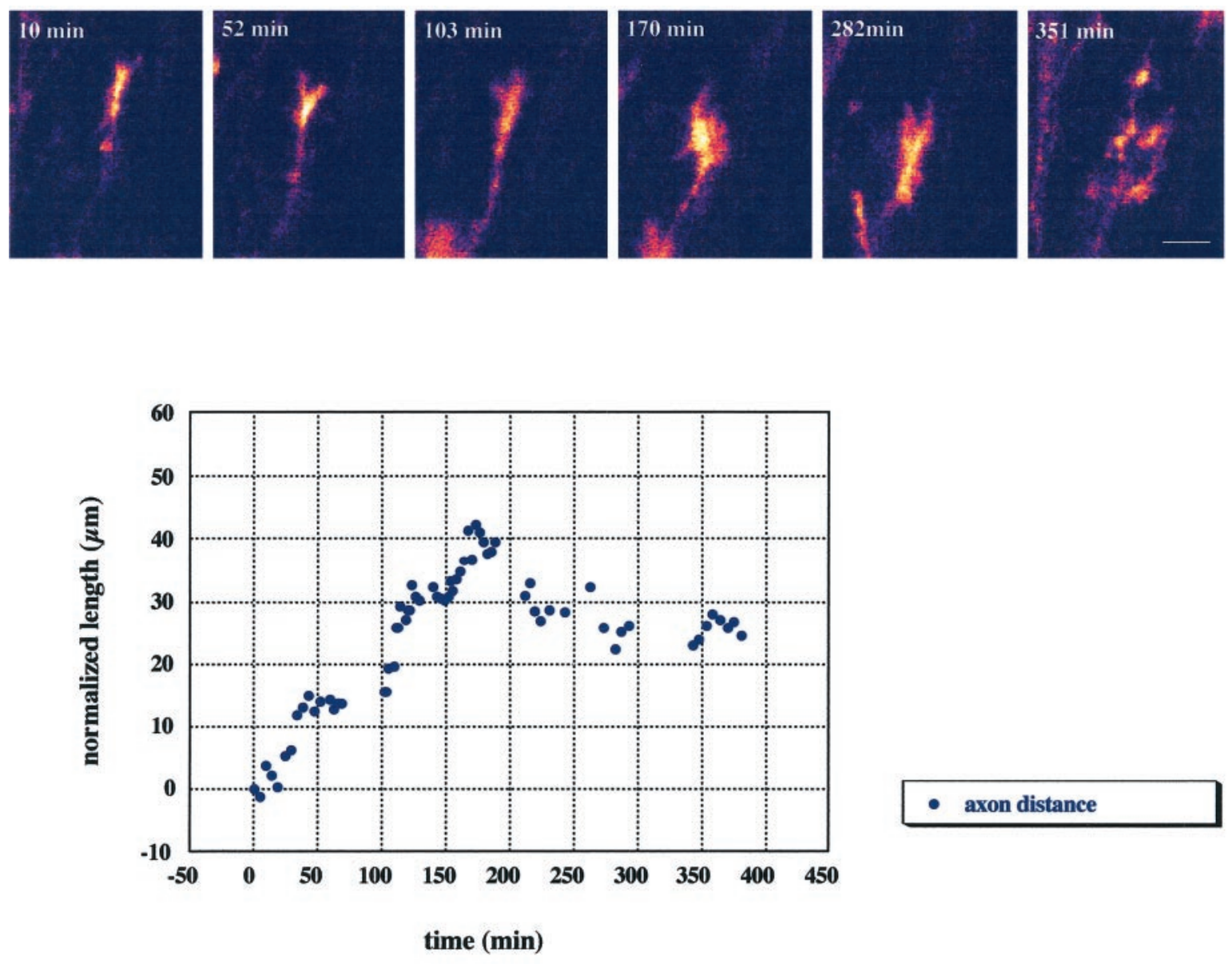

- axon distance

Figure 8. Example of "transition" behavior in an axon for which the leading segment is at the border between IC and VIZ, in a slice obtained from an E17 embryo. The panels at the top are single-frame confocal images of the growth cone. The data points in the graph illustrate the net advance of the axon during the period of observation. Scale bar, $10 \mu \mathrm{m}$.

short periods of advance (Bovolenta and Mason, 1987; Godement et al., 1994; Mason and Wang, 1997; Chan et al., 1998). The duration of pauses differs between studies, ranging from 15 to 60 min (Sretavan and Reichardt, 1993; Chan et al., 1998) up to several hours (Godement et al., 1994). Also in the chiasm, axons are often observed to change their trajectory, usually by selective remodeling of different parts of the motile apparatus of the growth cone, immediately after a pause (Sretavan and Reichardt, 1993; Godement et al., 1994; Chan et al., 1998). Such behaviors have also been encountered in other transition points (Harris et al., 1987; Kaethner and Stuermer, 1992; Halloran and Kalil, 1994; Yamamoto et al., 1997) and are consistently similar to our findings of thalamic axons reaching the VIZ. Taken together, they suggest that axons in this area are responding individually to a new set of local cues and imply that the dorsolateral border of the differentiating basal ganglia constitutes a decision region for thalamic axons.

The molecular signals that trigger these responses are presently unknown. The changes in growth cone morphology and growth patterns occur over a fairly restricted region, arguing against a global diffusion gradient generated from cortical target regions. Instead they imply localized guidance cues-which are likely to include inhibitory factors, to account for the longer and more frequent pauses, but also attractive factors, to account for the expanded size and increased complexity of growth cones (Le- tourneau, 1975, 1982; Caudy and Bentley, 1986a; Kuhn et al., 1995; Isbister and O'Connor, 1999). A localized increase in affinity could either provide direct guidance information to thalamic axons (Letourneau, 1975; Gundersen, 1985; Hammarback et al., 1985; O'Connor et al., 1990), or it may serve mainly to enlarge the surface area of their growth cones, thus increasing their potential to integrate spatially divergent signals (Isbister and O'Connor, 1999).

Finally, the pronounced pauses in this area could reflect cellular interactions and the formation of specialized membrane contacts between thalamic axons and other axonal or cellular elements, much like the behavior of retinal axons in the chiasm (Bovolenta and Mason, 1987; Marcus and Mason, 1995; Marcus et al., 1995; Colello and Coleman, 1997). Such contacts might trigger subsequent rearrangements of surface receptors that would contribute to the frequent changes in trajectory we observed in this region (Dodd et al., 1988; Seeger et al., 1993; Stoeckli and Landmesser, 1998).

\section{Concluding remarks}

Our results suggest that thalamic axons use other axons as a preferred substrate through the bulk of the striatum, although they appear to retain the ability to respond individually to the available cues. The findings also indicate that, as thalamic axons reach the border between basal and dorsal telencephalon, this 
close association with other axons is no longer sufficient to carry them further, because axons go through repeated cycles of extension, pause, and retraction and extend filopodia in different directions before resuming forward advance, usually in a different direction. This suggests that growth cones are receiving and integrating a novel set of cues to make the next pathfinding decision. The molecular signals responsible for the observed behaviors are unknown but in all likelihood will consist of a combination of attractive and repulsive cues presented in a precise spatial and temporal arrangement. The experimental design and results presented in this study provide, for the first time, the basis for examining the separate and combined effects of such guidance cues in an accessible yet intact preparation of the thalamocortical pathway.

\section{REFERENCES}

Agmon A, Connors BW (1991) Thalamocortical responses of mouse somatosensory (barrel) cortex in vitro. Neuroscience 41:365-379.

Agmon A, Yang LT, O'Dowd DK, Jones EG (1993) Organized growth of thalamocortical axons from the deep tier of terminations into layer IV of developing mouse barrel cortex. J Neurosci 13:5365-5382.

Agmon A, Yang LT, Jones EG, O’Dowd DK (1995) Topological precision in the thalamic projection to neonatal mouse barrel cortex. J Neurosci 15:549-561.

Bagnard D, Betz H, Götz M, Püschel AW, Bolz J (1996) Do semaphorins act as guidance molecules for afferent and efferent projections in the developing cerebral cortex? Soc Neurosci Abstr 22:1473.

Bagnard D, Lohrum M, Uziel D, Püschel AW, Bolz J (1998) Semaphorins act as attractive and repulsive guidance signals during the development of cortical projections. Development 125:5043-5053.

Bernardo KL, Ma PM, Woolsey TA (1986) In vitro labeling of axonal projections in the mammalian central nervous system. J Neurosci Methods 16:89-101.

Bicknese AR, Sheppard AM, O'Leary DD, Pearlman AL (1994) Thalamocortical axons extend along a chondroitin sulfate proteoglycan-enriched pathway coincident with the neocortical subplate and distinct from the efferent path. J Neurosci 14:3500-3510.

Bolz J, Novak N, Staiger V (1992) Formation of specific afferent connections in organotypic slice cultures from rat visual cortex cocultured with lateral geniculate nucleus. J Neurosci 12:3054-3070.

Bovolenta P, Dodd J (1990) Guidance of commissural growth cones at the floor plate in embryonic rat spinal cord. Development 109:435-447.

Bovolenta P, Mason C (1987) Growth cone morphology varies with position in the developing mouse visual pathway from retina to first targets. J Neurosci 7:1447-1460.

Brittis PA, Lemmon V, Rutishauser U, Silver J (1995) Unique changes of ganglion cell growth cone behavior following cell adhesion molecule perturbations: a time-lapse study of the living retina. Mol Cell Neurosci 6:433-449.

Catalano SM, Robertson RT, Killackey HP (1991) Early ingrowth of thalamocortical afferents to the neocortex of the prenatal rat. Proc Natl Acad Sci USA 88:2999-3003.

Catalano SM, Robertson R, Killackey HP (1996) Individual axon morphology and thalamocortical topography in developing rat somatosensory cortex. J Comp Neurol 366:36-53.

Caudy M, Bentley D (1986a) Pioneer growth cone morphologies reveal proximal increases in substrate affinity within leg segments of grasshopper embryos. J Neurosci 6:364-379.

Caudy M, Bentley D (1986b) Pioneer growth cone steering along a series of neuronal and non-neuronal cues of different affinities. J Neurosci 6:1781-1795.

Chan SO, Wong KF, Chung KY, Yung WH (1998) Changes in morphology and behaviour of retinal growth cones before and after crossing the midline of the mouse chiasm - a confocal microscopy study. Eur J Neurosci 10:2511-2522.

Colamarino SA, Tessier-Lavigne M (1995) The axonal chemoattractant netrin-1 is also a chemorepellent for trochlear motor axons. Cell 81:621-629.

Colello SJ, Coleman LA (1997) Changing course of growing axons in the optic chiasm of the mouse. J Comp Neurol 379:495-514.

Crandall JE, Caviness Jr VS (1984) Thalamocortical connections in newborn mice. J Comp Neurol 228:542-556.
Dodd J, Morton SB, Karagogeos D, Yamamoto M, Jessell TM (1988) Spatial regulation of axonal glycoprotein expression on subsets of embryonic spinal neurons. Neuron 1:105-116.

Emerling DE, Lander AD (1994) Laminar specific attachment and neurite outgrowth of thalamic neurons on cultured slices of developing cerebral neocortex. Development 120:2811-2822.

Ghosh A, Shatz CJ (1992a) Involvement of subplate neurons in the formation of ocular dominance columns. Science 255:1441-1443.

Ghosh A, Shatz CJ (1992b) Pathfinding and target selection by developing geniculocortical axons. J Neurosci 12:39-55.

Ghosh A, Antonini A, McConnell SK, Shatz CJ (1990) Requirement for subplate neurons in the formation of thalamocortical connections. Nature 347:179-181.

Giger RJ, Wolfer DP, De Wit GM, Verhaagen J (1996) Anatomy of rat semaphorin III/collapsin-1 mRNA expression and relationship to developing nerve tracts during neuroembryogenesis. J Comp Neurol 375:378-392.

Godement P, Mason CA (1993) Guidance of retinal fibers in the optic chiasm. Perspect Dev Neurobiol 1:217-225.

Godement P, Wang LC, Mason CA (1994) Retinal axon divergence in the optic chiasm: dynamics of growth cone behavior at the midline [Erratum (1995) 15:table of contents, issue 3]. J Neurosci 14:7024-7039.

Gundersen RW (1985) Sensory neurite growth cone guidance by substrate-adsorbed nerve growth factor. J Neurosci Res 13:199-212.

Halloran MC, Kalil K (1994) Dynamic behaviors of growth cones extending in the corpus callosum of living cortical brain slices observed with video microscopy. J Neurosci 14:2161-2177.

Hammarback JA, Palm SL, Furcht LT, Letourneau PC (1985) Guidance of neurite outgrowth by pathways of substratum-adsorbed laminin. J Neurosci Res 13:213-220.

Harris WA, Holt CE, Bonhoeffer F (1987) Retinal axons with and without their somata, growing to and arborizing in the tectum of Xenopus embryos: a time-lapse video study of single fibers in vivo. Development 101:123-133.

Holt CE (1989) A single-cell analysis of early retinal ganglion cell differentiation in Xenopus: from soma to axon tip. J Neurosci 9:3123-3145.

Hornberger MR, Dutting D, Ciossek T, Yamada T, Handwerker C, Lang S, Weth F, Huf J, Wessel R, Logan C, Tanaka H, Drescher U (1999) Modulation of EphA receptor function by coexpressed ephrinA ligands on retinal ganglion cell axons. Neuron 22:731-742.

Hubener M, Gotz M, Klostermann S, Bolz J (1995) Guidance of thalamocortical axons by growth-promoting molecules in developing rat cerebral cortex. Eur J Neurosci 7:1963-1972.

Isbister CM, O'Connor TP (1999) Filopodial adhesion does not predict growth cone steering events in vivo. J Neurosci 19:2589-2600.

Isbister CM, Tsai A, Wong ST, Kolodkin AL, O'Connor TP (1999) Discrete roles for secreted and transmembrane semaphorins in neuronal growth cone guidance in vivo. Development 126:2007-2019.

Kaethner RJ, Stuermer CA (1992) Dynamics of terminal arbor formation and target approach of retinotectal axons in living zebrafish embryos: a time-lapse study of single axons. J Neurosci 12:3257-3271.

Kageyama GH, Robertson RT (1993) Development of geniculocortical projections to visual cortex in rat: evidence early in growth and synaptogenesis. J Comp Neurol 335:123-148.

Kim GJ, Shatz CJ, McConnell SK (1991) Morphology of pioneer and follower growth cones in the developing cerebral cortex. J Neurobiol 22:629-642.

Kuhn TB, Schmidt MF, Kater SB (1995) Laminin and fibronectin guideposts signal sustained but opposite effects to passing growth cones. Neuron 14:275-285.

Letourneau PC (1975) Cell-to-substratum adhesion and guidance of axonal elongation. Dev Biol 44:92-101.

Letourneau PC (1982) Nerve fiber growth and its regulation by extrinsic factors. In: Neuronal development, pp 213-254. New York: Plenum.

Llirbat B, Godement P (1999) Positional specificities of retinal growth cones in the mouse superior colliculus. Eur J Neurosci 11:2103-2113.

Lopresti V, Macagno ER, Levinthal C (1973) Structure and development of neuronal connections in isogenic organisms: cellular interactions in the development of the optic lamina of Daphnia. Proc Natl Acad Sci USA 70:433-437.

Luo Y, Raible D, Raper JA (1993) Collapsin: a protein in brain that induces the collapse and paralysis of neuronal growth cones. Cell 75:217-227.

Marcus RC, Mason CA (1995) The first retinal axon growth in the 
mouse optic chiasm: axon patterning and the cellular environment. J Neurosci 15:6389-6402.

Marcus RC, Blazeski R, Godement P, Mason CA (1995) Retinal axon divergence in the optic chiasm: uncrossed axons diverge from crossed axons within a midline glial specialization. J Neurosci 15:3716-3729.

Mason CA, Wang LC (1997) Growth cone form is behavior-specific and, consequently, position-specific along the retinal axon pathway. J Neurosci 17:1086-1100.

Matthes DJ, Sink H, Kolodkin AL, Goodman CS (1995) Semaphorin II can function as a selective inhibitor of specific synaptic arborizations. Cell 81:631-639.

McConnell SK, Ghosh A, Shatz CJ (1989) Subplate neurons pioneer the first axon pathway from the cerebral cortex. Science 245:978-982.

Messersmith EK, Leonardo ED, Shatz CJ, Tessier-Lavigne M, Goodman CS, Kolodkin AL (1995) Semaphorin III can function as a selective chemorepellent to pattern sensory projections in the spinal cord. Neuron 14:949-959.

Métin C, Godement P (1996) The ganglionic eminence may be an intermediate target for corticofugal and thalamocortical axons. J Neurosci $16: 3219-3235$.

Métin C, Deleglise D, Serafini T, Kennedy TE, Tessier-Lavigne M (1997) A role for netrin-1 in the guidance of cortical efferents. Development 124:5063-5074.

Miller B, Chou L, Finlay BL (1993) The early development of thalamocortical and corticothalamic projections. J Comp Neurol 335:16-41.

Miller B, Sheppard AM, Bicknese AR, Pearlman AL (1995) Chondroitin sulfate proteoglycans in the developing cerebral cortex: the distribution of neurocan distinguishes forming afferent and efferent axonal pathways. J Comp Neurol 355:615-628.

Mitrofanis J, Baker GE (1993) Development of the thalamic reticular and perireticular nuclei in rats and their relationship to the course of growing corticofugal and corticopetal axons. J Comp Neurol 338:575-587.

Mitrofanis J, Guillery RW (1993) New views of the thalamic reticular nucleus in the adult and the developing brain. Trends Neurosci $16: 240-245$.

Molnár Z, Blakemore C (1991) Lack of regional specificity for connections formed between thalamus and cortex in coculture. Nature 351:457-477.

Molnár Z, Blakemore C (1995) How do thalamic axons find their way to the cortex? Trends Neurosci 18:389-397.

Molnár Z, Blakemore C (1999) Development of signals influencing the growth and termination of thalamocortical axons in organotypic culture. Exp Neurol 156:363-393.

Molnár Z, Adams R, Blakemore C (1998) Mechanisms underlying the early establishment of thalamocortical connections in the rat. J Neurosci 18:5723-5745.

O'Connor TP, Duerr JS, Bentley D (1990) Pioneer growth cone steering decisions mediated by single filopodial contacts in situ. J Neurosci 10:3935-3946.

Polleux F, Giger RJ, Ginty DD, Kolodkin AL, Ghosh A (1998) Patterning of cortical efferent projections by semaphorin-neuropilin interactions. Science 282:1904-1906.

Püschel AW, Adams RH, Betz H (1996) The sensory innervation of the mouse spinal cord may be patterned by differential expression of and differential responsiveness to semaphorins. Mol Cell Neurosci 7:419-431.

Raper JA, Bastiani M, Goodman CS (1983) Pathfinding by neuronal growth cones in grasshopper embryos. I. Divergent choices made by the growth cones of sibling neurons. J Neurosci 3:20-30.
Richards LJ, Koester SE, Tuttle R, O’Leary DD (1997) Directed growth of early cortical axons is influenced by a chemoattractant released from an intermediate target. J Neurosci 17:2445-2458.

Rose D, Chiba A (1999) A single growth cone is capable of integrating simultaneously presented and functionally distinct molecular cues during target recognition. J Neurosci 19:4899-4906.

Roskies AL, O'Leary DD (1994) Control of topographic retinal axon branching by inhibitory membrane-bound molecules. Science 265:799-803.

Schlaggar BL, O'Leary DD (1994) Early development of the somatotopic map and barrel patterning in rat somatosensory cortex. J Comp Neurol 346:80-96.

Seeger M, Tear G, Ferres-Marco D, Goodman CS (1993) Mutations affecting growth cone guidance in Drosophila: genes necessary for guidance toward or away from the midline. Neuron 10:409-426.

Serafini T, Colamarino SA, Leonardo ED, Wang H, Beddington R, Skarnes WC, Tessier-Lavigne M (1996) Netrin-1 is required for commissural axon guidance in the developing vertebrate nervous system. Cell 87:1001-1014.

Skaliora I, Singer W, Betz H, Püschel AW (1998) Differential patterns of semaphorin expression in the developing rat brain. Eur J Neurosci 10:1215-1229.

Sretavan DW, Reichardt LF (1993) Time-lapse video analysis of retinal ganglion cell axon pathfinding at the mammalian optic chiasm: growth cone guidance using intrinsic chiasm cues. Neuron 10:761-777.

Stoeckli ET, Landmesser LT (1995) Axonin-1, Nr-CAM, and Ng-CAM play different roles in the in vivo guidance of chick commissural neurons. Neuron 14:1165-1179.

Stoeckli ET, Landmesser LT (1998) Axon guidance at choice points. Curr Opin Neurobiol 8:73-79.

Tosney KW, Landmesser LT (1985) Growth cone morphology and trajectory in the lumbosacral region of the chick embryo. J Neurosci $5: 2345-2358$.

Tuttle R, O'Leary DD (1998) Neurotrophins rapidly modulate growth cone response to the axon guidance molecule, collapsin-1. Mol Cell Neurosci 11:1-8.

Tuttle R, Schlaggar BL, Braisted JE, O'Leary DD (1995) Maturationdependent upregulation of growth-promoting molecules in developing cortical plate controls thalamic and cortical neurite growth. J Neurosci 15:3039-3052.

Varela-Echavarria A, Tucker A, Püschel AW, Guthrie S (1997) Motor axon subpopulations respond differentially to the chemorepellents netrin-1 and semaphorin D. Neuron 18:193-207.

Williams RW, Borodkin M, Rakic P (1991) Growth cone distribution patterns in the optic nerve of fetal monkeys: implications for mechanisms of axon guidance. J Neurosci 11:1081-1094.

Winberg ML, Mitchell KJ, Goodman CS (1998) Genetic analysis of the mechanisms controlling target selection: complementary and combinatorial functions of netrins, semaphorins, and IgCAMs. Cell 93:581-591.

Yamamoto N, Kurotani T, Toyama K (1989) Neural connections between the lateral geniculate nucleus and visual cortex in vitro. Science 245:192-194.

Yamamoto N, Yamada K, Kurotani T, Toyama K (1992) Laminar specificity of extrinsic cortical connections studied in coculture preparations. Neuron 9:217-228.

Yamamoto N, Higashi S, Toyama K (1997) Stop and branch behaviors of geniculocortical axons: a time-lapse study in organotypic cocultures. J Neurosci 17:3653-3663. 